\title{
Medical students value-adding to general practice
}

\author{
A qualitative study
}

\section{Anthea Dallas, Wei Gin Samantha Hiew, Brittany Kay, Hannah Jackson, Katharine Reid, Jennifer Presser, Robyn Woodward-Kron}

\section{Background and objective}

Medical students can make valuable contributions to patient care during clinical placements. The aim of this study was to investigate student perceptions of the value of general practice placements for their learning, and their sense of contribution during their placements.

\section{Methods}

The study used a qualitative design to gather in-depth student perspectives on learning and contributions, using focus groups of final-year medical students on general practice placement.

\section{Results}

Thirteen students participated in one of three focus groups. Students reported valuable learning affordances in general practice and identified contributions to improved workflow, rapport-building, patient education, encouraging clinician reflection and shared learning between general practitioner and student.

\section{Discussion}

Student perspectives of value-adding on general practice placements, and a deeper understanding of these learning environments, may enable general practice supervisors to facilitate placements that maximise these benefits.
CLINICAL PLACEMENTS are a key component of medical curricula and are vital in preparing work-ready graduates. ${ }^{1}$ The benefits of well-supervised clinical placements are documented from the perspectives of both students and educators. ${ }^{2-4}$ Clinical placements provide opportunities for Work Integrated Learning, while regular, constructive feedback can foster development. ${ }^{5}$ Further, research suggests that when students have a sense of responsibility and accountability, for example independently seeing patients, their motivation is heightened, and learning experiences are more effective. ${ }^{6}$ In general practice, with its multidisciplinary, holistic healthcare approach, the benefits of clinical placements for students include: exposure to undifferentiated presentations, refinement of diagnostic skills and an improved understanding of preventive care, chronic disease management, mental health and population health. ${ }^{7}$

However, for general practitioners (GPs), the dominant discourse about placements is often one of burden for the clinic. ${ }^{2,3,8}$ GPs cite barriers to accepting students on clinical placements, including uncertainty about the level of skills and training required to be medical educators. ${ }^{1,9}$ GPs also note concerns regarding cognitive overload, ${ }^{2,3}$ financial disincentive ${ }^{8-10}$ and increased workload and time pressures due to activities such as seeking patient consent for student involvement and teaching obligations. ${ }^{2}$ Patients often enjoy their involvement in student education and benefit from the longer consultations. However, GPs note concerns for patients who experience inhibition when a student is present, particularly for psychosocial or sensitive issues. ${ }^{2,3,11}$

The barriers to accepting students on general practice placements should be viewed in the context of a clinical placement shortage. ${ }^{12,13}$ Clinical placements have become a challenge for medical schools worldwide, ${ }^{14}$ including in Australia, where clinical placement capacity has been challenged by an increase in the number of medical schools. ${ }^{13,15}$ The expansion of the medical workforce has been driven by a growing and ageing population, increased prevalence of chronic disease and doctor shortage, particularly in regional and rural areas. ${ }^{16}$

An alternative to the burden discourse is the notion of value-added medical education, ${ }^{17}$ where student experiential learning is aligned with the key goals of the health service: to provide safe, high-quality patient care. Seen in this way, student contributions to patient care should be expected during general practice placements, adding value rather than burden to the work of the general practice. At present, however, little is known of the student perspective, with 
the existing literature mainly focused on the perspectives of supervisors, , $^{2,3,18}$ patients ${ }^{11,19}$ and, to some extent, general practice trainees/registrars. ${ }^{20}$ This study aimed to identify how medical students perceive their learning and contributions on general practice placements.

\section{Methods}

The study was based on components of an existing methodology, which was designed to examine the benefits of clinical placements for student learning and contributions to health services. ${ }^{21}$ This methodology was piloted in hospital placements and adapted to the general practice context, with a Communities of Practice theoretical lens informing the design and analysis. ${ }^{22}$ The design used focus groups to capture the multifaceted and contextualised accounts of how students learn and contribute to patient care through work on placements, and to encourage discussion of a variety of viewpoints. $^{23}$

\section{Participants and recruitment}

Participants were final-year medical students of a five-year undergraduate medical course in Australia who had completed their general practice placement. All students from one urban clinical school $(n=48)$ were invited by email to participate in a focus group after they had completed their placements.

\section{Data}

The researchers adapted the focus group question schedule from the Clinical Placement Research Framework ${ }^{21}$ for the general practice setting (Appendix 1, available online only). The focus groups were conducted throughout 2019 by the medical student on the research team (BK) together with another researcher (AD). This pairing was designed to foster student involvement and perspective, and to monitor any researcher bias. The three sessions were audio-recorded, transcribed verbatim and de-identified.

\section{Data analysis}

The qualitative data from the focus group transcripts were analysed thematically as described by Braun and Clarke. ${ }^{24}$ Preliminary coding was guided by the coding schema developed from the Clinical Practice Research Framework ${ }^{21}$ and applied to the data by $\mathrm{AD}, \mathrm{BK}$ and $\mathrm{HJ}$ working independently. Codes were refined and some added to reflect the general practice context. Differences in interpretation were resolved by discussion within the coding team. Themes were discussed and agreed on in consultation with the broader research team (RWK and JP).

Reflexivity was enhanced by having multiple investigators involved at each stage of analysis articulating the influences of their assumptions and position on their interpretation of the data (medical student BK; academic GPs involved in organising general practice placements $\mathrm{AD}$ and $\mathrm{HJ}$; researcher RWK).

This project was approved by the Tasmanian Social Sciences Human Research Ethics Committee (reference: H0017638).

\section{Results}

Thirteen students participated in one of three focus groups. This represents approximately one-third of the cohort on placement in that academic year.

The findings of the thematic analysis from the focus groups are reported first for students' perceptions of learning opportunities in general practice, and then for perceived contributions. The two main themes for learning opportunities were: learning affordances in general practice and learning gains. Themes for student contributions were: workflow; improved patient experience through spending time, rapport-building and educating patients; and shared learning between student and general practice supervisor.

\section{Learning affordances in general practice}

The term 'affordances' relates to the features or properties of a placement that improve the experience for students. Students reflected on the value of general practice placements for particular areas of learning, which included: learning about common conditions, chronic disease management, longitudinal care, undifferentiated presentations, preventive care, understanding of the role of the GP in the health system, referral pathways, interactions with allied health, and the relationship between community-based primary care and inpatient hospital care. Students identified the opportunity for observing patient-centred care, and the structure of general practice placements (eg integration into the practice team, close contact with patients and supervisors, experiencing continuity of care) as being valuable for learning.

I think that's one of the things that [general practice] rotation gives you. It's that 'global' view. That - while there's a patient sitting in front of you with that problemthat may not be why they are actually there. There's all this external stuff in their life that comes up. [Participant (P) 2, Focus Group (FG) 2]

The best part of [general practice] is having one-on-one time with a consultant. It's one of the few opportunities where you get to spend a whole day with someone whom you can ask questions directly, and get immediate feedback. [P4, FG1]

\section{Learning gains}

'Learning gains' refers to students' perceptions of their improved consultation and communication skills; for example, learning about building rapport, time management or consultation structure. Learning gains were reportedly achieved both by opportunities for practice, as well as by observing the supervising GP.

Wave consulting [where the student sees the patient independently before presenting to the supervisor] was obviously probably high yield for $m y$ learning, because you're there asking the questions, synthesising the diagnosis and that sort of stuff. [P4, FG3]

It's those little skills you pick up by watching them that can sort of alter your practice ... and look a bit more professional... whilst a normal student looks clunky. [P4, FG1] 
This rotation really opened my eyes to the importance of open-ended questions at the start. I realised that the person had been waiting in the waiting room for 15-30 minutes pre-orchestrating what they were going to say. [P1, FG3]

Students reported developing their clinical reasoning skills as they observed and managed undifferentiated or evolving presentations. The experience of independent consulting with feedback from the supervisor was particularly valued for developing their confidence with these skills.

\section{Having lots of that one-on-one patient time, and practice being the patient's doctor, and taking all the relevant information, and formulating a management plan, and putting that into place, and practising articulating that to the patient ... with my GP's input ... having to modulate my practice, I gained a lot from that. [P6, FG3]}

\section{Student contributions}

Students perceived that they contributed to the work of general practice by performance of tasks useful for clinic workflow, assisting with history taking, physical examinations, procedures, typing and nurse support.

With the wave consulting, that helped the doctor get through on time... made me feel quite useful as well. [P2, FG1]

I also helped the practice nurse a lot ... by doing immunisations, helping her with dressings... They were understaffed so I thought I was quite useful then. [P2, FG1]

Parallel or 'wave' consulting was cited frequently as one of the areas in which students were able to contribute to workflow. Although students were aware that they slowed the doctor down, students believed that, with experience, they could improve efficiency with increased autonomy.

Initially when you were wrapping your head around things, you might have been slowing down the practice to start off with.
But once you have some practice, you're consulting in tandem, and I think that increased efficiency. [P6, FG3]

Students perceived that their time spent with patients was an important contribution, both in its quantity and quality. Many students reflected that, as they had more time and less familiarity with the patient, the quality and depth of their history-taking and health promotion activities made a positive contribution to patient care.

While the doctors saw one patient, I saw the next patient, so it kind of helped to speed things up. Patients didn't have to wait long to be seen by someone. I think it is better to talk with someone in the room, rather than have them sitting out there in the waiting room. So we provided a better experience for the patients. [P1, FG2]

I think there were a few times where I took more expansive social or mental [health] histories, because I had a bit more time to spend with the patients. [P4, FG3]

Student presence in the consultation was also perceived as adding to patient health literacy.

A lot of doctors explained things a lot better when I was there ... and the patients reflected on that and enjoyed it ... it helped [the patient] to understand what was going on and why the doctor was doing it. [P2, FG1]

Students often described themselves as a 'bridge' between patient and doctor in terms of power differential, medical knowledge or generational differences.

I found that younger patients particularly liked having a younger clinician to talk to about what was going on with their bits, rather than someone who looked like their mum or dad. [P4, FG3]

Many students had a sense that their presence and input led to an improved patient experience by providing time and space for patients to express their thoughts. They described their role as that of providing comfort, emotional support and a 'friendly face' when interacting with patients and their families.

A theme that suggested a bidirectional benefit was the perceived sense of shared learning between the student and their supervising GP. The student may have facilitated clinician self-reflection by asking questions to broaden the scope of discussion or allowing supervisors to explain or review their own processes. The role of the student as an extra clinician or junior colleague was perceived by students to contribute to the clinical reasoning and reflective processes of their supervising GPs.

GPs would normally sit and give me a little summary of the patient before I saw the patient, so it gave them a really good opportunity to review the patient and see where they were at ... 'oooh, they haven't had this'... so it was a good opportunity for them to do that preventative health and screening. [P2, FG1]

We've been taught different things, and have different attitudes to different aspects of medicine. And so having conversations about different parts of practice, I thought was very valuable. And sometimes we found that there were better ways of doing things. And sometimes we found out that what we've been taught probably wasn't the best option. And sometimes we found that neither of us had the right answer, and that there was a completely different thing out there for best practice. So I found that valuable, and the clinicians I had-where we had meaningful discussions around this-probably found benefit too. [P4, FG3]

Through observing their supervising GPs and interacting with patients, students noticed aspects of the clinical presentation that contributed positively to patient management (eg noticing medication errors; suggesting diagnoses, investigations or preventative activities). Other common themes included offering 'a second pair of eyes' and contributing knowledge appropriate to the student's level of learning.

A second pair of eyes... I picked up a few medications that shouldn't be used in conjunction with each other. [P4, FG1] 
When the GP is asking questions, you're also thinking about stuff. There was a time when ... the GP was thinking about a certain diagnosis, but I had seen something else, so I went and told the GP 'I think this is what it is' and she gave a handout to the patient, and he read through it and said 'this is exactly what I've got!' [P3, FG1]

\section{Discussion}

The findings of this study further our understanding of the learning affordances specific to general practice and the types of contributions that students make during clinical placements. Reframing students as adding value to clinical care as they participate in learning activities may reduce the perception of students as a burden in the clinical environment and increase the awareness of students and supervisors to maximise opportunities for student contributions.

Students reported learning affordances specific to the general practice context and contributions to workflow, patient experience and shared learning with the supervisor, as well as specific contributions to patient care, including diagnosis and management. In the analysis of the themes from the qualitative data, it became apparent that there was a synergy between student learning and student contributions. When students perceived that they made a positive contribution to the clinical work of the practice in patient care, these students expressed an increased value of learning activities. One clear example of this synergy is student attitudes to parallel/wave consulting. In the quotes above, students described contributing to clinic workflow and efficiency, as well as spending quality time with patients, while learning highly valued skills (eg communication and clinical reasoning) and receiving feedback. A second example of this synergy is that of shared learning between GP and student. As the GP is observed by and teaches the student, they reflect on their practice and may receive the benefits of a 'second pair of eyes' on the patient, while the student learns from observing the skill of the GP and by having their questions answered and knowledge affirmed. The more students participate and contribute, the more they learn. The nature of general practice placements facilitated this synergy, especially when students were given opportunities to contribute.

The present findings about the benefits of student contributions strengthen the conclusions of previous studies in other clinical placement contexts. ${ }^{4}$ Inclusion in cohesive teams, while having opportunities for meaningful contributions to patient care, are learning affordances valued highly by students. ${ }^{6}$ There are a variety of empirical studies of students contributing to primary care, including student-run clinics ${ }^{25}$ and patient education programs, ${ }^{26}$ highlighting that such activities are valued by students, allowing for learning opportunities and providing patient care of adequate quality. ${ }^{25}$ The present study expands on these findings to show the valuable contributions of students in the regular learning activities of general practice placement, and it challenges the narrative of 'students as burden'. $2,3,8$

Studies of Australian GPs reported similar themes from the supervisor perspective, including students' contributions to supervisors' clinical reasoning and reflection. ${ }^{2}$ From the patient perspective, studies show largely positive attitudes to student teaching during consultations ${ }^{11,19}$ and patients' perceptions that students do not detract from the quality of service they receive. ${ }^{27}$ In the present study, the examples of student contributions suggest that student presence may not just have neutral impact - rather, students may improve the quality of healthcare delivery, as well as overall patient experience.

\section{Strengths, limitations and areas for further study}

The study design was based on an existing framework and built on previous research in hospital settings, ${ }^{21}$ thus allowing for the exploration of learning and contributions in the general practice context. The inclusion of a student researcher provided the student lens in the data analysis and enacted the researchers' belief in meaningful student contributions in all aspects of practice. While limited as a single-site qualitative study, the design allowed for depth of student experiences to be captured. Because students self-selected to participate in the study, it is possible the results reflect a positive bias. A question regarding students' attitudes before and after general practice placement would be of interest in future studies. The study could have been extended and improved by the addition of the clinician and patient perspective. Economic analyses of the impact of student clinical placements would also be worthy of further investigation - a recent UK study has quantified the cost of medical student placements in general practice, ${ }^{28}$ but there has been no comparable work in the Australian setting. ${ }^{29}$

\section{Implications for practice}

Helping students to develop skills to maximise the specific learning affordances in their clinical placements requires an awareness of what these might be in each learning context. The findings highlight some of the unique features of general practice for learning. Students should be guided in terms of optimising these learning opportunities (eg how to learn through observation of doctors and patients; how best to consult independently while seeking supervisor feedback). Medical educators should embrace the potential for students to make meaningful contributions to patient care and provide scaffolds accordingly.

\section{Conclusion}

General practice placements are essential in the training of the future healthcare workforce. Maximising the benefits of these placements for medical student learning and contribution requires support and infrastructure to ensure the feasibility of hosting students. Empowering medical students to make genuine contributions during their clinical placements is a paradigm shift with potential benefits for student learning, general practices, patients and health systems. Educators and supervisors can reframe the discourse 
around clinical placements in general practice to highlight the value added by students.

\section{Authors}

Anthea Dallas FRACGP, MClinEd, MPH, MBBS (Hons), BSc, Academic Lead - Community Placements, Tasmanian School of Medicine, University of Tasmania, Hobart, Tas

Wei Gin Samantha Hiew BBioMedSc, Melbourne Medical School, University of Melbourne, Melbourne, Vic

Brittany Kay BMedSc (Hons), Tasmanian School of Medicine, University of Tasmania, Hobart, Tas Hannah Jackson FRACGP, MBBS, Senior Lecturer in Medicine, Tasmanian School of Medicine, University of Tasmania, Hobart, Tas

Katharine Reid PhD, MPsych, MSc (Applied Statistics), BSc (Hons), BA, Director of Evaluation and Quality, Department of Medical Education, Melbourne Medical School, University of Melbourne, Melbourne, Vic

Jennifer Presser PhD, FRACGP, MHealthProfEd, MBBS, BSc (Hons), MBBS, Academic Lead - MBBS, Tasmanian School of Medicine, University of

Tasmania, Hobart, Tas

Robyn Woodward-Kron PhD, MA, BA, GradDipArts, Director of Research, Department of Medical Education, Melbourne Medical School, University of Melbourne, Melbourne, Vic

Competing interests: JP is a member of the Australian Journal of General Practice Editorial Advisory

Committee.

Funding: None.

Provenance and peer review: Not commissioned, externally peer reviewed.

Correspondence to:

anthea.dallas@utas.edu.au

\section{Acknowledgments}

The authors would like to thank Drs Chance Pistoll, Phyllis Lau and Mark Lavercombe for their assistance with recruitment, and the students who participated in the research.

\section{References}

1. Strand $P$, Edgren $G$, Borna $P$, Lindgren $S$, Wichmann-Hansen G, Stalmeijer RE. Conceptions of how a learning or teaching curriculum, workplace culture and agency of individuals shape medical student learning and supervisory practices in the clinical workplace. Adv Health Sci Educ Theory Pract 2015;20(2):531-57. doi: 10.1007/ s10459-014-9546-0.

2. Sturman N, Régo P, Dick ML. Rewards, costs and challenges: The general practitioner's experience of teaching medical students. Med Educ 2011;45(7):722-30. doi: 10.1111/j.13652923.2011.03930.x.

3. Baldor RA, Brooks WB, Warfield ME, O'Shea K. A survey of primary care physicians' perceptions and needs regarding the precepting of medical students in their offices. Med Educ 2001;35(8):789-95. doi: 10.1046/j.13652923.2001.00980.x

4. Dornan T, Littlewood S, Margolis SA, Scherpbier A, Spencer J, Ypinazar V. How can experience in clinical and community settings contribute to early medical education? A BEME systematic review. Med Teach 2006;28(1):3-18. doi: 10.1080/01421590500410971.
5. Sheehan D, Bagg W, de Beer W, et al. The good apprentice in medical education. N Z Med J 2010;123(1308):89-96

6. Kandiah DA. Perception of educational value in clinical rotations by medical students. Adv Med Educ Pract 2017;8:149-62. doi: 10.2147/AMEP. S129183.

7. Thistlethwaite JE, Kidd MR, Hudson JN. General practice: A leading provider of medical student education in the 21st century? Med J Aust 2007;187(2):124-28. doi: 10.5694/j.1326-5377.2007. tb01160.x.

8. Hudson JN, Weston KM, Farmer EA. Medical students on long-term regional and rural placements: What is the financial cost to supervisors? Rural Remote Health 2012;12(2):1951.

9. Radford J. A survey of strategies for increasing the number of medical learners in all Tasmanian general practices. FoHPE 2017;18(2):76. doi: 10.11157/fohpe.v18i2.225.

10. Laurence CO, Black LE, Karnon J, Briggs NE. To teach or not to teach? A cost-benefit analysis of teaching in private general practice. Med J Aust 2010;193(10):608-13. doi: 10.5694/j.13265377.2010.tb04072.x.

11. Larsen K, Perkins D. Training doctors in general practices: A review of the literature. Aust J Rural Health 2006;14(5):173-77. doi: 10.1111/j.14401584.2006.00803.x.

12. Australian Medical Council Medical School Accreditation Committee. Clinical placements in undergraduate medical education: Applying AMC standards to the assessment of clinical teaching placements. Canberra, ACT: AMC, 2007.

13. Joyce CM, Stoelwinder JU, McNeil JJ, Piterman L. Riding the wave: Current and emerging trends in graduates from Australian university medical schools. Med J Aust 2007;186(6):309-12. doi: 10.5694/j.1326-5377.2007.tb00907.x.

14. Alberti $\mathrm{H}$, Atkinson J. Twelve tips for the recruitment and retention of general practitioners as teachers of medical students. Med Teach 2018;40(3):227-30. doi: 10.1080/0142159X.2017.1370082.

15. Hays RB, McKinley RK, Sen Gupta TK. Twelve tips for expanding undergraduate clinical teaching capacity. Med Teach 2019;41(3):271-74. doi: 10.1080/0142159X.2018.1429587.

16. Health Workforce Australia. Australia's Future Health Workforce - Doctors. Canberra, ACT: Australian Government Department of Health, 2014.

17. Lin SY, Schillinger E, Irby DM. Value-added medical education: Engaging future doctors to transform health care delivery today. J Gen Intern Med 2015;30(2):150-51. doi: 10.1007/s11606-0143018-3.

18. Pearce R, Laurence CO, Black LE, Stocks N. The challenges of teaching in a general practice setting. Med J Aust 2007;187(2):129-32. doi: 10.5694/j.1326-5377.2007.tb01161.x.

19. Salisbury K, Farmer EA, Vnuk A. Patients' views on the training of medical students in Australian general practice settings. Aust Fam Physician 2004;33(4):281-83.

20. Kleinitz A, Campbell D, Walters L. General practice registrar perceptions on training medical students. Aust Fam Physician 2014;43(1):64-67.

21. Molloy E, Lew S, Woodward-Kron R, et al. Final project report for the Medical Deans of Australia and New Zealand (MDANZ): Medical student clinical placements as sites of learning and contribution. Melbourne, Vic: University of Melbourne, 2018.
22. Lave J, Wenger E. Situated learning: Legitimate peripheral participation. Cambridge, UK: Cambridge University Press, 1991.

23. Hansen EC. Successful qualitative health research. Berkshire, UK: Open University Press, 2006.

24. Braun V, Clarke V. Using thematic analysis in psychology. Qual Res Psychol 2006;3(2):77-101. doi: 10.1191/1478088706qp063oa.

25. Schutte T, Tichelaar J, Dekker RS van Agtmael MA, de Vries TP, Richir MC. Learning in student-run clinics: A systematic review. Med Educ 2015;49(3):249-63. doi: 10.1111/medu.12625.

26. Vijn TW, Fluit CRMG, Kremer JAM, Beune T, Faber MJ, Wollersheim $\mathrm{H}$. Involving medical students in providing patient education for real patients: A scoping review. J Gen Intern Med 2017:32(9):1031-43. doi: 10.1007/s11606-0174065-3.

27. Price R, Spencer J, Walker J. Does the presence of medical students affect quality in general practice consultations? Med Educ 2008;42(4):374-81. doi: 10.1111/j.1365-2923.2008.03016.x.

28. Rosenthal J, McKinley RK, Smyth C, Campbell JL. The real costs of teaching medical students in general practice: A cost-collection survey of teaching practices across England. Br J Gen Pract 2019;70(690):e71-77. doi: 10.3399/ bjgp19X706553.

29. Bowles K, Haines T, Molloy E, et al. The costs and benefits of providing undergraduate student clinical placements for a health service organisation: An Evidence Check rapid review brokered by the Sax Institute for the Hunter and Coast Interdisciplinary Training Network through the Health Education Training Institute (HETI). Glebe, NSW: Sax Institute, 2015. 